\title{
El estado mexicano de Chiapas: ¿Qué ha cambiado en veinte años?
}

\section{The Mexican state of Chiapas: What has changed in twenty years?}

\author{
Agustín Ávila Romero * \\ José Luis Sulvarán López ** \\ León Enrique Ávila Romero ***
}

Fecha de recepción: 22 de mayo de 2014

Concepto de evaluación: 26 de junio de 2014

Fecha de aprobación: 15 de septiembre de 2014

Doctor en Ciencias Sociales y Desarrollo Rural. Profesor titular de la Universidad Intercultural de Chiapas. Unidad Académica Multidisciplinaria Las Margaritas. México. Correo Electrónico: agustinavila@yahoo.com

** Doctor en Ciencias Sociales y Humanísticas. Profesor titular de la Universidad Intercultural de Chiapas. San Cristóbal de las Casas, México. Correo electrónico: jsulvarn@gmail.com

*** Doctor en Ciencias Agrarias. Profesor titular de la Universidad Intercultural de Chiapas. San Cristóbal de las Casas, México. Correo electrónico: leonavilaromero@yahoo.com.mx 


\section{Resumen}

En el presente texto se hace un recorrido sobre las causas económicas y sociales que posibilitaron la rebelión zapatista hace veinte años, para mostrar que este hecho ocasionó la llegada creciente de recursos económicos al estado de Chiapas y exponer, a su vez, como se utilizaron los dineros por parte de los municipios oficiales y el Gobierno del estado. Se concluye que las finanzas públicas de Chiapas son sumamente débiles y que pese a la creciente inyección de capital que ha recibido, el estado se encuentra sobre endeudado y en condiciones de marginación y pobreza similares a las de hace dos décadas.

Palabras clave: Chiapas, finanzas públicas, conflicto armado, EZLN, deuda pública.

JEL: E60, F51, H63.

\section{Abstract}

This paper looks over the economic and social causes that allowed the zapatista rebellion 20 years ago, to show that this fact caused the increased arrival of economic resources to the State of Chiapas, and to expose, in turn, how the money by the Government of the State and the official municipalities were used. It is concluded that the public finances of Chiapas are extremely weak and that despite the increased capital infusion that it has received, the State is indebted and in similar conditions of marginalization and poverty of those of the two decades ago.

Keywords: Chiapas, armed conflict, EZLN, public finance, public debt. 


\section{INTRODUCCIÓN}

Han pasado veinte años desde que el primero de enero de 1994, un ejército compuesto mayoritariamente por indígenas y denominado Ejército Zapatista de Liberación Nacional (EZLN), tomara por la vía armada varias cabeceras municipales del estado de Chiapas, México, y con ello iniciara una guerra directa contra "el mal gobierno", que duró doce días. En la actualidad mantiene una lucha política centrada en el reconocimiento de los derechos y culturas indígenas.

En esos veinte años es importante preguntarse ¿Qué ha cambiado en Chiapas a raíz del alzamiento zapatista? ¿Han mejorado realmente las condiciones de vida de la población? ¿Cuál ha sido el manejo de los cuantiosos recursos que han llegado a dicha entidad tanto del gobierno federal como de los organismos de cooperación internacional? En este artículo nos acercamos a la realidad del Chiapas contemporáneo, haciendo énfasis en el manejo de las finanzas públicas en el contexto de la economía neoliberal.

\section{METODOLOGÍA}

Para la elaboración de esta investigación se utilizaron técnicas documentales que permitieron revisar la bibliografía y hemerografía existente sobre el tema; así mismo, se acudió al Instituto Federal de Acceso a la Información Pública (IFAI) con el objetivo de recabar datos referentes a la cuenta pública del estado, incluyendo a los municipios oficiales, para hacer frente a la opacidad y ausencia de transparencia en que se mueven las distintas entidades públicas de la entidad chiapaneca. 


\section{LAS CAUSAS DEL ALZAMIENTO ZAPATISTA}

El 1 de enero de 1994 salió a la luz pública en Chiapas el movimiento armado del Ejército Zapatista de Liberación Nacional (EZLN). Las causas que llevaron a los zapatistas a tomar las armas las han explicado ellos mismos con claridad. Por ejemplo, en la entrevista que el subcomandante Marcos concedió a Yvon Le Bot (1997), señala:

nosotros pensamos que hay varios ingredientes que explican el crecimiento masivo del EZLN. Uno es el fraude de 1988 contra el cardenismo, que significa la cancelación de una posibilidad de transición pacífica para cierto sector de los indígenas, el más politizado, sobre todo, los de la Unión de Uniones. La ARIC. Otro es la caída de los precios del café. Otro, unas epidemias muy grandes que hubo en la selva y que mataron a muchos niños de mononucleosis y otras enfermedades. Nosotros siempre sospechamos que provenían de bombardeos químicos sobre Guatemala que el viento traía para acá, porque eran inexplicables. Empezaron a morir cientos de niños en unas semanas, no podemos explicar por qué. Y el otro elemento es una incursión del ejército federal a la selva. Entra en búsqueda de mariguana o quién sabe qué, se mete así dentro de la selva, hace una especie de peinados desastrosos para ellos porque pronto dejaron de ser invencibles. La gente los vio y los vio bien jodidos, porque la montaña te hace mierda, "¿esos son los soldados?", les vamos a partir la madre". Esto rompió un poco el miedo, la sacralización de los aviones y los ataques. Pues resulta que estos soldaditos están tan jodidos como yo a la hora que les pasa la montaña encima. Esto se combinó con un auge de los asesinatos de las guardias blancas, que empezaron a arrinconar a la gente con la disyuntiva siguiente: o peleas o te mato... nosotros pensábamos que estábamos convenciendo a la gente. En realidad, era otro el elemento que la estaba convenciendo; la reforma de Salinas al artículo 27, y eso era lo último que faltaba. Se cancela el reparto agrario, ahora toda la tierra, incluso los ejidos, se pueden comprar y vender. Entonces ya no hay esperanza, se acabó. Ya solo queda la lucha armada.

Las causas estructurales del alzamiento ponen énfasis en la opresión étnica y la discriminación que existe en Chiapas, conjuntamente con la presencia de una base social indígena dispuesta a la protesta desde hace siglos. Los agravios son muchos, repetidos y dolorosamente continuados, incluso, en un país que tuvo la primera revolución del siglo. Estos agravios están descritos y analizados con detalle en el libro Resistencia y utopía de Antonio García de León (1985). 
Cuando arribaron los españoles a Chiapas, encontraron una gran fuerza cultural que, en ese entonces, defendió palmo a palmo a las comunidades ${ }^{1}$ y que ahora continúa defendiendo a sus descendientes. Los indígenas de los Altos de Chiapas hablan cinco lenguas distintas, mayoritariamente tsotzil, tseltal, tojol-ab'al, chol y zoque. A excepción de esta última, todas las demás derivan de la familia lingüística máyense, y hoy reivindican sus culturas y el derecho a seguirlas desarrollando. Por otra parte, Chiapas como estado tiene una identidad distintiva, ya que dispone de su propia historia. Hay que recordar que hasta el primer cuarto del siglo XIX, algunas de sus regiones pertenecían a la Capitanía General de Guatemala, por lo cual tenían formas políticas distintas y una estructura estamental en la que los grupos étnicos se han mezclado muy poco.

Asimismo, un factor muy importante de diferencia, es que la Revolución mexicana no triunfó en Chiapas. Las fuerzas de Venustiano Carranza no lograron imponer criterios sociales ni reformas a la tenencia de la tierra, porque los terratenientes mestizos-ladinos impidieron todo tipo de cambio al declararse revolucionarios, para así, mantener el control del poder y evitar el reparto agrario. En consecuencia, la reforma agraria fue mínima, especialmente en los Altos, donde habitaba la mayor parte de la población indígena.

Así, el proceso de construcción de un nuevo Estado no fue percibido por las clases populares de Chiapas como un movimiento de liberación social, como la posibilidad de recuperar la autonomía económica, política y cultural perdida después de cuatro siglos de expropiación. El pueblo chiapaneco simplemente no creyó en las promesas de justicia social difundidas por los diferentes gobiernos revolucionarios y mucho menos comprendió el ideario político del nuevo Estado, ya que persistió el tradicional sistema de explotación basado en la servidumbre, como la caciquil, figura del terrateniente exportador acostumbrado al poder sin límite y a la ganancia fácil.

En contra de esa situación nada pudo el socialismo nacional del constitucionalismo triunfante encabezado por el sonorense Salvador Alvarado. El poder de los terratenientes y la desconfianza indígena se constituyeron en una especie de contrarrevolución que logró mantener los viejos estilos de dominación política $\mathrm{y}$ explotación económica: la hacienda $\mathrm{y}$ el peonaje.

A partir del gobierno de Álvaro Obregón, las grandes familias que detentaban el poder en Chiapas establecieron una alianza con el gobierno federal para mantener sus privilegios. El pacto continúa hasta

Los mayas y los grupos indígenas de Chiapas fueron los últimos grupos en ser sometidos por los españoles 
la actualidad. La comunidad indígena volvió a ser despojada de sus tierras y continua siendo explotada a través de esquemas de trabajo servil:

entre 1940 y 1941, la tenencia de la tierra se mantuvo prácticamente intacta. El gobierno cardenista apenas aceptó algunos latifundios. Cuando México se vio obligado a industrializarse para incrementar la producción nacional... más del 50 $\%$ de las tierras censadas en Chiapas estaban en poder del $2.6 \%$ de los propietarios locales. (Vázquez, 1994)

Desde entonces, y hasta la fecha, la situación de la población campesina en la región, mayoritariamente indígena, lejos de mejorar, empeoró. De los cinco millones de hectáreas que se repartieron entre 1940 y 1970 en Chiapas, más de tres millones, las de mejor calidad, fueron entregadas en propiedad individual a los ganaderos y madereros organizados en asociaciones; mientras que las hectáreas restantes, prácticamente improductivas, se les otorgaron a los campesinos bajo la forma de ejidos. Y si a esto se agrega la construcción, a partir de 1960, de tres hidroeléctricas, que implicó la expropiación de miles de hectáreas cultivables, ejidales y comunales de indígenas zoques y choles, junto a la caída de los precios internacionales del cacao, café y algodón, así como las medidas neoliberales adoptadas por el gobierno federal en los ochenta, que cancelaron las instituciones sociales que regulaban el mercado interno (Inmecafe y Conasupo), entonces, hay que decir que la situación agraria en Chiapas se tornó, en no pocos casos, insoportable.

Tan solo en Chiapas se concentra el $27 \%$ del rezago agrario del país, dentro del rubro de terrenos nacionales hay más de 4,600 casos y 1'150 de inafectabilidad agraria; 503 solicitudes de dotación y ampliación ejidal; 78 solicitudes de nuevos centros de población; 29 expedientes de titulación de bienes comunales; 72 resoluciones presidenciales pendientes de ejecutar; 4 investigaciones de fraccionamientos simulados, 559 planos definitivos; 176 amparos; 332 juicios privativos de nuevas adjudicaciones; y 361 conflictos interparcelarios. (RAN, 2002)

Mientras en 1994, alrededor de seis mil familias de ganaderos eran propietarias de más de 3'000,000 de hectáreas, casi la mitad de la superficie del estado, el sector social, que también abarcaba poco más de 3'000,000 de hectáreas, estaba conformado por casi 200,000 ejidatarios y comuneros, de cuyo trabajo dependían aproximadamente un millón de personas, equivalente a la tercera parte de la población del estado. En la zona del conflicto, el 0.01 $\%$ de los propietarios tenía en sus manos el $15 \%$ de la tierra, mientras que el otro 85 $\%$ de ella se repartía entre decenas de miles de indígenas.

En relación con esta situación, la investigadora rural, Adriana López Monjardin (1994) señala: "los pueblos desalojados o incendiados, los dirigentes 
torturados o asesinados no han sido de los finqueros. En estos 20 años, los indígenas chiapanecos podrían contar por siglos el tiempo que tantos de ellos han pasado en la cárcel...".

Esto lo explica de la siguiente forma Pablo González Casanova (1995):

En el origen de la rebelión también está el desarrollo de Chiapas. Desde los años treinta había empezado la crisis de los latifundios cafetaleros. Los peones acasillados huían a otras regiones menos desgraciadas. En los cincuenta vino la liberación de los peones por las haciendas ganaderas en formación. Estas, ya no necesitaban sus servicios. En la década de los 70 terminó virtualmente “el peón acasillado". Chiapas se convirtió en gran productor de electricidad y petróleo. De nueva cuenta los peones "libres" abandonaron las fincas cafetaleras, cañeras, maiceras, e incluso ganaderas. Se fueron a los trabajos de electricidad y petróleo, de presas y de carreteras. Otros se encaminaron a la Selva para hacerse a una vida pobre pero propia; son los que hoy habitan por el territorio donde se mueve el Ejército Zapatista de Liberación Nacional.

Los habitantes que llegaron a la selva ya habían sido expulsados de otras tierras, provenían de los valles centrales, pues con la construcción de presas, más de cien mil personas tuvieron que emigrar. Sus tierras quedaron bajo el agua. La explotación del petróleo inutilizó grandes extensiones convirtiéndolas en eriales o veneros. Alrededor de cincuenta mil personas se vieron obligadas a salir. La crisis económica de finales de los 70 y principios de los 80 , disminuyeron las fuentes de trabajo urbanas dando como resultado el despido de 200.000 trabajadores, quienes fueron obligados prácticamente a volver a la tierra que habían dejado. Para colmo, en 1982, hizo erupción el volcán “Chichonal” e inutilizó setenta mil hectáreas. Cerca de veinte mil pobladores debieron reubicarse. Muchos iniciaron el éxodo a la Selva Lacandona. No sabían que de allí también intentarían expulsarlos. Y por todos los medios.

De esta forma, la tierra en Chiapas -fuente de sustento principal de los "pobres"- se volvió cada vez más escasa. Al mismo tiempo, hubo un crecimiento natural de la población. En el área rural creció a una tasa de $3.6 \%$ anual. Hacia 1985, en las regiones con disponibilidad familiar de 16 hectáreas, se pasó a tener en promedio menos de 4 hectáreas por familia. El crecimiento de la población fue factor muy importante para el empobrecimiento de los campesinos que ya eran pobres, sobre todo porque se combinó con el despojo de tierras y recursos de parte de las compañías y los terratenientes. Aun antes de ser muchos, los campesinos ya carecían de créditos, de asistencia técnica y de mercados humanamente aceptables. Su producción era y sigue siendo extensiva, con técnicas de "rozatumba y quema", y siembras frecuentes que aumentaron las "tierras cansadas". 
Los conflictos agrarios se acentuaron en el estado. A principios de los ochenta, 400 fincas y latifundios fueron invadidos por los campesinos; cien mil sobrevivieron como precaristas, setenta mil solicitaron tierras al Departamento Agrario sin que nadie los atendiera.

Los reclamos e invasiones de tierra continuaron. A principios de los noventa, Chiapas tenía sin satisfacer el $27 \%$ de las demandas de tierras de todo el país. De los 10,600 expedientes en trámite en la Secretaría de la Reforma Agraria, tres mil eran de Chiapas. Tras largos y costosos procesos, los campesinos no lograban nada. Cuando había una resolución presidencial en su favor, no era ejecutada. Los "sin tierra" cobraron cada vez más conciencia de que mientras a ellos los habían empobrecido, marginado y excluido, los grandes propietarios tenían latifundios simulados que ni siquiera explotaban. Como no solo realizaron movilizaciones de protesta, sino que empezaron a ocupar algunas parcelas y a cultivarlas, el carácter violento de la respuesta de los finqueros se volvió sistemático. Si antes atacaban violentamente a los indios para quitarles sus derechos, ahora los atacaban "con más razón” y con mucha saña acusándolos de violar la sagrada propiedad privada, la paz social y el Estado de derecho. El resultado fue desastroso: líderes encarcelados y asesinados, familias y comunidades desalojadas y perseguidas, tierras recuperadas por el ejército o por las guardias blancas. En todas partes subsiste el recuerdo de las respuestas violentas: en
Simojovel, Huitiupan, Sabanilla, Yajalón, Chilón, Ocosingo, Las Margaritas. Aun así, había la esperanza de que un día se aplicara la Constitución y se hiciera justicia. Para alimentar la ilusión, el gobierno, de vez en cuando, compraba algunas tierras a los propietarios y se las entregaba a los indígenas.

En síntesis, en la historia de Chiapas existe una estructura agraria en la que el sector privado ha acaparado la superficie de tierra de mejor calidad. Es más, entre estos destacan los ganaderos como el sector privilegiado. Ellos son los actores principales en los conflictos agrarios.

\section{Neoliberalismo y causas coyunturales del alzamiento}

Junto con esta pobreza y atraso político ancestral se combinaron, como anotamos anteriormente, los cambios estructurales puestos en marcha en 1982 y que favorecieron un desarrollo desigual en el país, tanto en los sectores económicos como en lo relativo a la concentración del ingreso por parte del capital financiero.

Bajo este contexto, observamos a Chiapas a inicios de los noventa como la entidad federativa con más alto índice de marginación. De acuerdo con los datos oficiales, esta región del sureste mexicano registró el porcentaje más alto de población superior a los 15 años sin primaria completa, el de mayor número de viviendas sin energía eléctrica y en hacinamiento, y el de mayor porcentaje de población ocupada con un ingreso menor 
a dos salarios mínimos. Anivel municipal, más del $80 \%$ de los ayuntamientos chiapanecos observaron índices de marginación alta y muy alta.

Esta situación de evidente atraso social se reflejó con toda claridad en los espacios económicos. El gran indicador que expresó la marginación de la entidad lo constituyó la relación establecida entre la población y su asentamiento. Mientras a nivel nacional más del $70 \%$ de la población estaba asentado en predios urbanos, en Chiapas el porcentaje no llegaba al $30 \%$. En término generales, se mantenía en la región el carácter predominantemente agrario que existía en el país antes de la Revolución: aproximadamente el $90 \%$ se encontraba concentrada en los sectores primarios y terciarios (57 \% y $27 \%$ respectivamente), mientras que el industrial solo el $10 \%$.

Ante este panorama, los cambios estructurales neoliberales crearon a nivel local nuevas condiciones sociales y económicas, a las cuales tuvieron que enfrentarse los grupos indígenas de Los Altos y la Selva Lacandona.

En el caso de la Selva Lacandona, gran número de los habitantes residentes fueron migrantes de otras zonas del estado y cuyas características de no estar contenidos por estructuras tradicionales de autoridad conjuntamente con la dispersión de sus asentamientos, permitieron -junto con la geografía- el asentamiento de campamentos clandestinos.
Ahora bien, por este proceso de colonización que se fue dando poco a poco en la selva, los habitantes encontraron muchos problemas para la producción, la comercialización de sus productos, el abasto, el cuidado de los enfermos, la educación de los hijos, el transporte y la comunicación. Por ello, les resultaba indispensable el apoyo del gobierno para el cultivo, la ganadería o la comercialización; y la ineficiencia y los errores burocráticos en la oportunidad de acceso a insumos o a ventas significaron hambre en las familias y frustración cuando el gobierno no cumplía con los apoyos prometidos.

\section{El precio del café, el crecimiento demográfico y la crisis ganadera: los detonantes}

A partir de 1973, los pequeños productores de café pudieron vender parte de su cultivo a una agencia gubernamental: el Instituto Mexicano del Café (INMECAFÉ). La posición de este decayó con la crisis económica de los ochenta. Como muchas de las agencias gubernamentales de ese periodo, se vio afectado por la ineficiencia, la corrupción y la mala administración.

La respuesta del Gobierno de Carlos Salinas fue iniciar el proceso de privatización en 1989. El INMECAFÉ se retiró inmediatamente de la adquisición y comercialización y redujo su actividad a la asistencia técnica. A pesar de que la reforma se diseñó originalmente para 
incluir a las organizaciones de productores en el cambio de infraestructura, el plan careció de la necesaria voluntad política y mucha infraestructura quedó en manos privadas.

Junto con ello, la caída del precio del café en más del $65 \%$, antes del levantamiento armado zapatista, disminuyeron los ingresos de la gran mayoría de los productores indígenas, que casi en su totalidad era su único ingreso monetario y, en el caso de los trabajadores asalariados, una de las más importantes fuentes de empleo.

Esta disminución se debió, sobre todo, a que el Estado mexicano dejó de intervenir en el mercado agropecuario nacional e internacional; así, cuando el precio del café bajó a nivel global, nuestro país lo que hizo fue desaparecer al Instituto Mexicano del Café, que intervenía en el mercado de exportación de este producto. Los productores de Chiapas, Oaxaca y otros estados, tuvieron que enfrentarse, de la noche a la mañana, a un mercado internacional cuyo funcionamiento, mecanismos, tramitaciones e incluso formas de obtener información, desconocían por completo. Lo brutal de esta repentina apertura a la competencia la han vivido los campesinos como traición por parte del Gobierno.

Además, en ausencia del INMECAFÉ, los costos de comercialización tuvieron que ser absorbidos por los productores mismos, o alternativamente con la reaparición de intermediarios privados no regulados, conocidos como coyotes.

En síntesis, para 1994 vivían y trabajaban en Chiapas 16,939 productores de café; el $93 \%$ de ellos eran dueños de predios menores a las dos hectáreas. De 1989 a 1994, el precio internacional del café había disminuido significativamente. Las exportaciones del aromático mexicano se contrajeron de 3' 739,000 sacos en el período 1988-89 a 1'157,000 para el período 1992-93, al mismo tiempo que su cotización pasó de 130 dólares por quintal en 1989, a unos 50 dólares en 1993.

Además de la caída de los precios internacionales y la caída de la productividad, un factor que afectó fuertemente a los productores chiapanecos fue la sobrevaluación del peso mexicano, puesto que el café se vende en el mercado internacional en dólares. La sobrevaluación del peso castigó a los productores de manera drástica, ya que en diciembre de 1988 la paridad peso-dólar era de 2,297 pesos por dólar, en diciembre de 1993, fue de 3.2 pesos $^{2}$. La inflación durante el mismo período fue de $89.3 \%$. Es decir, el productor recibió dólares baratos y tuvo que comprar sus insumos con pesos caros. En otras palabras:

...para la mayoría del millón de indios de Chiapas, el acceso a la tierra y el cultivo de maíz y café forman la base de su economía y de su cultura.

2 Recordemos que el Estado mexicano al dotar de autonomía al Banco de México eliminó tres ceros de la convertibilidad monetaria. 
Por esta razón, la reestructuración del sector cafetalero, el abandono de los productores de maíz en tierras de temporal, la firma del Tratado de Libre Comercio (TLC) y las modificaciones al artículo 27 de la constitución mexicana que regula la tenencia de la tierra han tenido un evidente impacto en la subsistencia y expectativas de la población rural e indígena. (Harvey, 1995)

El hecho de que el EZLN haya cronometrado su alzamiento para que coincidiera con la entrada en vigor del Tratado de Libre Comercio entre México, Estados Unidos y Canadá, demostró el vínculo que la misma guerrilla había deducido entre el modelo económico del Gobierno y su impacto social.

Otra de las causas del conflicto chiapaneco fue el deterioro salarial. Según José Luis Calva

vemos que los salarios agrícolas se han deteriorado de forma profunda en dicho estado, de 1980 a 1992 perdió 57.1 por ciento de su poder adquisitivo, lo que puso a miles de jornaleros agrícolas por debajo de la línea de sobrevivencia y los empujo claramente a las filas del EZLN. (Calva, 1993)

Uno de los efectos negativos que trajo consigo el retiro del apoyo estatal en el estado de Chiapas fue el deterioro del medio ambiente. Tan solo en la región de la selva, muchos campesinos, incapaces de capitalizar su producción, siguieron desmontando zonas boscosas por necesidades de subsistencia, como señala Harvey:

La rebelión en Chiapas puede verse como un indicio del grado de desesperación a que se ha llegado entre los pequeños agricultores, y como una advertencia de que la reestructuración neoliberal en las zonas rurales de México amenaza no sólo la subsistencia de los campesinos, sino la estabilidad política. (Harvey, 1995)

\section{Las respuestas en Chiapas al alzamien- to: contrainsurgencia, remunicipaliza- ción y división social}

En la estrategia de los Gobiernos federal y del estado para administrar el conflicto armado con el Ejército Zapatista de Liberación Nacional (EZLN), los derechos colectivos de los pueblos y, específicamente, el derecho a la libre determinación y autonomía contenida en los Acuerdos de San Andrés ${ }^{3}$, no fueron atendidos con igual interés como se hizo con otras situaciones. Además quedó claro, a partir de entonces, la utilización de los recursos públicos para promover la deserción en las comunidades zapatistas y la división de las comunidades que defendían su

Los Acuerdos de San Andrés fueron firmados entre el EZLN y el Gobierno federal en 1996. Desafortunadamente no han sido cumplidos por la parte gubernamental, lo que ha impedido la firma de la paz en Chiapas. 
territorio. Todo conjuntamente con la militarización y paramilitarización abierta que vivió el estado de Chiapas desde el año 1994 a la actualidad.

Asimismo, como resultado de las grandes luchas municipalistas por la alternancia y el desarrollo local, que se dieron en la década de los 90 en el estado de Chiapas, y el surgimiento de los municipios autónomos rebeldes zapatistas (MAREZ), se promovió un proceso de remunicipalización con la finalidad de atender las comunidades que se ubicaban en el radio de acción del EZLN.

Resultado de ello es un mosaico social que muestra a las comunidades indígenas profundamente debilitadas en su cohesión social por las crecientes divisiones políticas, religiosas y sociales. La supuesta alternancia de los gobiernos municipales oficiales no ha significado, en muchas poblaciones, un mejoramiento de sus condiciones de vida, sino nuevos terrenos de disputa por la gestión y uso de los recursos públicos:

La población indígena en Chiapas se caracteriza hoy por su creciente heterogeneidad. Internamente, tiene diferencias en materia de estructura sociodemográfica, estatus socioeconómico, estilos de vida, pautas de consumo, sistemas de valores, actitudes, percepciones y preferencias. A las diferencias de edad y género, se suman otras que tienen que ver con el lugar en que viven, ya sea en zonas urbanas o rurales, y a la región en el estado donde han nacido, ya sea las regiones Altos, Norte, Selva o Fronteriza. Aunque todos ellos comparten una identidad genérica como indígenas (ya sea por adscripción del Otro, o por auto adscripción), los proyectos comunes se han vuelto grupales, lo que ha dado lugar a una fragmentación de identidades. La comunidad homogénea dejó de ser el espacio para la satisfacción de necesidades humanas; ahora lo son los grupos segmentados. (Burguete, 2012, p. 65)

Por ejemplo, en los últimos años, los servicios municipales, la obra pública $\mathrm{y}$, en general, la política social, han sido motivo de conflictos internos en las comunidades. En parte, el conflicto irrumpió porque la manera en que se ejercieron los fondos públicos no estuvo acorde con la idea de beneficiar a toda la población, sino que se orientó con criterios focalizados. Advertimos que en la última década se presentó un giro importante en la política social, en tanto esta ya no se destinó a generar beneficios o progreso para las comunidades, como entidades colectivas amplias, sino que privilegió las acciones focalizadas, generalmente dispersas, lo que contribuyó a debilitar en la población la percepción sobre su carácter público, haciéndole perder legitimidad a la inversión gubernamental. Los programas focalizados beneficiaron a un número limitado de personas o familias, y no satisfacieron necesidades de carácter colectivo, sino que se canalizaron 
a fortalecer el progreso individual. La aplicación selectiva de los fondos fue motivo de conflicto. Creó rivalidades y enconos donde antes no los había, y generó divisiones en las familias, ya que los dineros y los beneficios personales no fueron resultado de esfuerzos colectivos. Muchos de los conflictos sociales que actualmente existen en Chiapas se originaron alrededor de la disputa de los fondos públicos (Burguete, 2012).

Ello tiene que ver, también, con una estrategia de contrainsurgencia que desde 1992 se opera en el estado de Chiapas y donde lo que se pretende es debilitar la resistencia de las comunidades indígenas a las políticas de ajuste estructural de corte neoliberal que se han impulsado en nuestro país y que ubican a Chiapas como un estado que aporta impresionantes recursos en el proceso de privatización de la naturaleza, acorde con los nuevos ejes de acumulación de capital.

Diversos cálculos nos hablan de un número importante de chiapanecos que continúan en posición de resistencia civil. Según diversas fuentes, este número podría ascender a 300,000 habitantes, muchos de ellos de entre los más pobres del estado. Esta estrategia, originada por los zapatistas, parece apuntar a exigir la refundación del orden estatal y a debilitar su legitimidad negándose a aceptar cualquier tipo de servicio público. Del otro lado, los grupos que se han declarado en resistencia brindan una oportunidad para la participación en la medida en que cuentan con sistemas de organización comunitaria sobre los cuales podrían articularse nuevas políticas públicas, en vez de generar nuevos sistemas para suplir la contribución del Estado.

Por ejemplo, los escasos resultados de la política social para remontar la pobreza en el estado son más una política de Estado que tiende a desterritorializar a los pobladores locales para obligarlos a emigrar, y es aquí donde surgen algunas preguntas que ha formulado correctamente la investigadora Burguete (2012):

¿Cómo explicar que pese al abundante flujo de recursos económicos en políticas públicas para la superación de la pobreza, éstas hayan tenido escaso impacto para modificar el orden de cosas que alimentaron el conflicto armado de 1994, caracterizado por la ausencia de servicios básicos en las regiones indígenas? ¿Qué factores intervienen?

En este marco, la segmentación de beneficiarios ha contribuido a la atomización comunitaria y a alentar los conflictos sociales. La respuesta pública no ha canalizado los recursos hacia las comunidades, sino hacia los grupos organizados. Lo anterior tuvo como consecuencia la dispersión y la atomización de los recursos públicos:

No obstante, el mayor problema de la dispersión de los fondos públicos no es la dispersión poblacional, sino 
la atomización de los presupuestos públicos por motivos de la ruptura del tejido social. Con frecuencia la confrontación interna que castiga con negar acceso a los servicios a los disidentes, creando "nuevas comunidades" (desterritorializadas) de disidentes, que a su vez reclaman los servicios de los que fueron excluidos, por razones de faccionalismo político y religiosos, profundizando la atomización comunitaria; hoy día característica en las regiones indígenas chiapanecas. Estos factores contribuyen a profundizar la dispersión de los fondos públicos que se aplican en los municipios, problemática que hoy es tan grave como el propio problema de la dispersión poblacional. (Burguete, 2012, p. 57)

Además, las capacidades para la participación efectiva y la eficiencia gubernamental fueron limitadas, tanto dentro del aparato del Estado como en la sociedad civil. Inmersos en una lógica diferente por muchos años, según la cual la participación era más una instancia nominal que real, muchos de los funcionarios públicos no contaron con la experiencia necesaria para diseñar y poner en marcha estrategias del gasto público eficientes. Por otra parte, han sido pocas las organizaciones de la sociedad civil con la capacidad necesaria para articularse en un esquema de alianzas con el estado. Muchas zonas de Chiapas tienen un déficit de sociedad civil organizada y requieren de una estrategia integral de fortalecimiento de capacidades.
Asimismo, la estrategia de remunicipalización oficial que se puso en marcha en julio de 1999 y con la cual se crearon los municipios de Aldama, Benemérito de las Américas, Marqués de Comillas, Montecristo de Guerrero, Maravilla Tenejapa, San Andrés Duraznal y Santiago del Pinar, se hizo también desde un enfoque de dispersión de fondos públicos, la atomización de los apoyos locales y claramente marcada por una lógica de contrainsurgencia para hacer frente al surgimiento de los Municipios Autónomos. Se construyeron así las propuestas de ayuntamientos como un espacio de disputa de grupos, facciones y asociaciones que constantemente se reestructuraban y extendían sus vínculos más allá de lo municipal, retomando muchos aspectos subjetivos y simbólicos de las localidades involucradas, los cuales fueron rescatados desde la visión oficial para legitimar el ejercicio del poder y la reorganización social municipal.

A estos nuevos municipios se les otorgaron recursos fiscales a través de un fideicomiso por 137 millones de pesos, lo cual permitió que operaran muchos de ellos, durante sus primeros años, con grandes ventajas en cuanto a las posibilidades de hacer uso discrecional de recursos públicos. En los hechos, la creación de estos nuevos municipios se ajustó a un plan de disputa de las bases campesinas en los municipios de Los Altos, Norte y Selva, que durante aquellos años se definió como zona de conflicto. 
Lo cierto es que los ayuntamientos de Chiapas han pasado de tener muy pocos recursos fiscales en cada año, sobre todo a partir de 1998, a poseer una mayor cantidad de recursos públicos. El resultado es que en lugar de mejorar plausiblemente la dotación de servicios públicos locales, la existencia de mayores recursos se ha traducido en un medio de enriquecimiento personal y grupal de diferentes facciones políticas ligadas al gobierno estatal de turno.
En la Figura 1 observamos como los recursos por casi 700 millones de pesos, que en el año de 1996 tuvieron todos los municipios de Chiapas, se incrementaron notablemente al pasar en el año 2012 a más de trece mil millones pesos, lo cual sustenta el supuesto de que los municipios de Chiapas cuentan con mayores recursos fiscales para atender las problemáticas de sus habitantes.

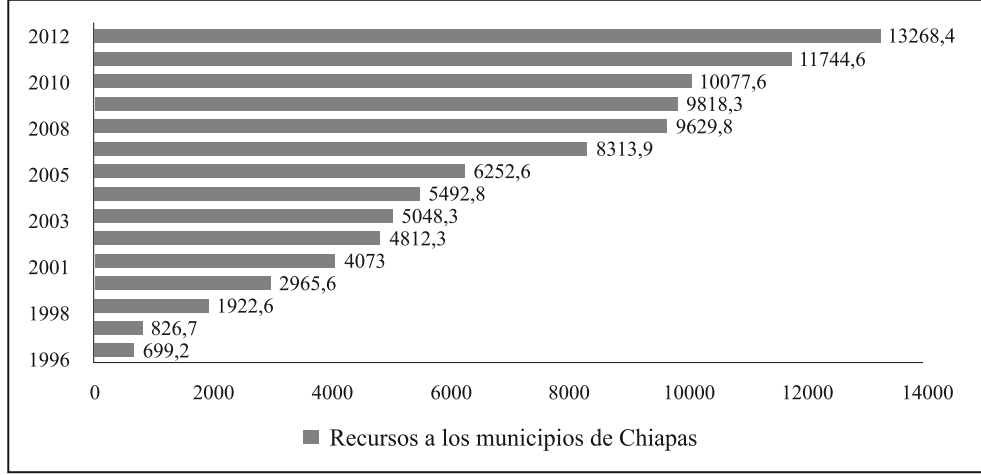

Figura 1. Recursos de los municipios de Chiapas 1996-2012 Millones de pesos corrientes Fuente: elaboración propia con base en las cuentas públicas del estado de Chiapas

Por ejemplo, para el año 2011, dentro del presupuesto de la federación, se aprobaron recursos a los municipios de las entidades federativas que fueron radicados de acuerdo con los lineamientos especificados en dicho decreto y en la Ley de Coordinación Fiscal, a través de transferencias y aportaciones a los 118 municipios de nuestra entidad.
Por ello, durante el ejercicio 2011, en los municipios del estado de Chiapas, se radicó la cantidad de 11744.6 millones de pesos distribuyéndose en forma transparente y oportuna con apego a las leyes establecidas. Las aportaciones principales y distribuidas a los municipios se encuentran bajo los siguientes conceptos: 


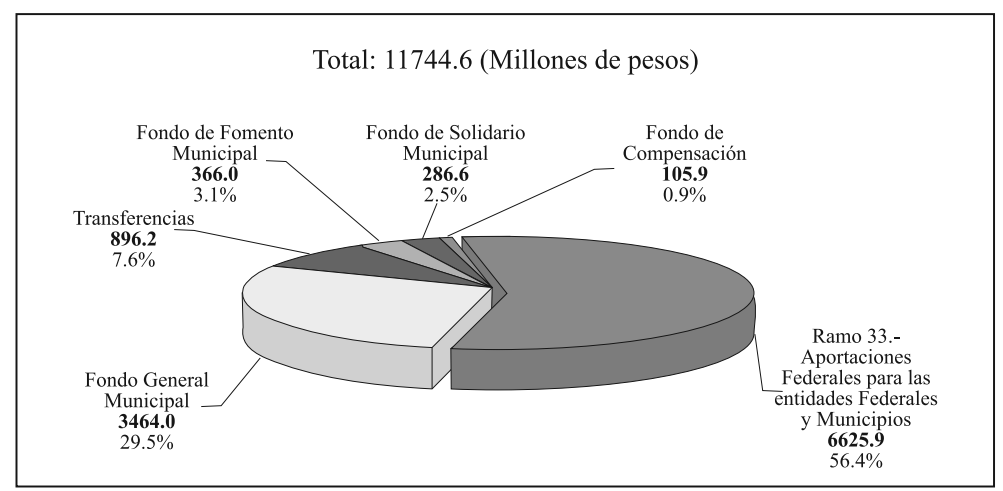

Figura 2. Transferencias de recursos a municipios de Chiapas, enero- diciembre 2011.

Fuente: Secretaria de Hacienda del Gobierno del estado de Chiapas

Esta mayor entrada de recursos públicos a los municipios de Chiapas no ha evitado que estas entidades recurran a un mayor endeudamiento, el cual ha puesto en riesgo el funcionamiento adecuado de muchos de ellos. Según la Auditoría Superior de la Federación, las deudas de los ayuntamientos de Chiapas existen en al menos 70 municipios que tienen pasivos financieros que oscilan entre los 900 y 1400 millones de pesos. Chiapas ocupa el lugar número 11 con mayor deuda municipal. Entre los principales deudores destaca el municipio de Tuxtla Gutiérrez, Tapachula, Ocosingo, Chilon, Las Margaritas, Tila y Palenque, entre otros.

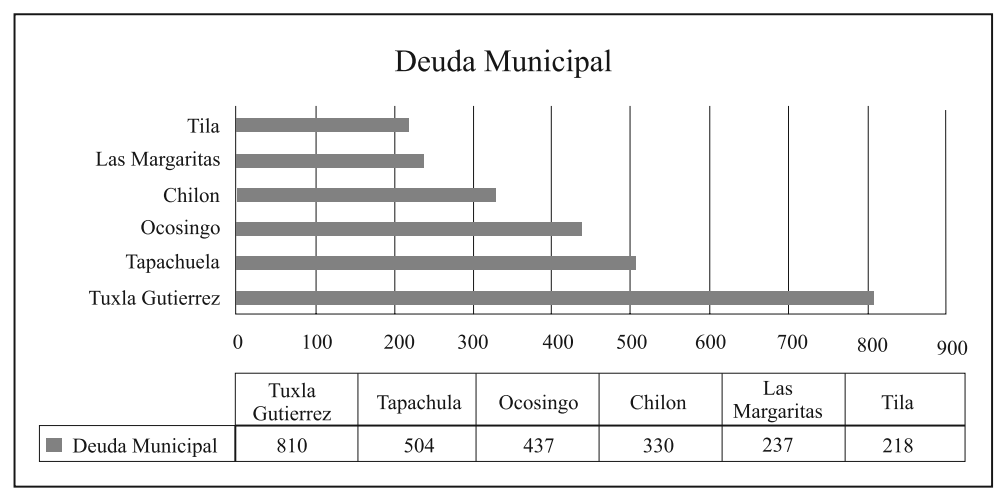

Figura 3. Municipios de Chiapas con mayor deuda. Millones de pesos

Fuente: elaboración propia con datos de la ASF 
Sí observamos esta dinámica a nivel municipal, constatamos que realmente es en épocas recientes cuando los ayuntamientos obtienen recursos fiscales crecientes.

FINANZAS PÚBLICAS EN CHIAPAS: LA DEBILIDAD ESTRUCTURAL DE LOS INGRESOS

El estado de Chiapas tiene en sus finanzas públicas grandes oportunidades, pero también, fuertes debilidades. Es indudable que en el transcurso de los últimos años ha aumentado fuertemente su presupuesto dependiendo fundamentalmente de las participaciones y aportaciones que realiza el Gobierno federal, ya que carece de una estructura de ingresos que le permita mantener sus niveles de gasto público.

El estado de Chiapas depende para su ejercicio del gasto público de las aportaciones, participaciones y transferencias que el Gobierno federal le aporta a través del Sistema Nacional de Coordinación Fiscal.

Hasta antes de 1980, en México existía una multiplicidad de impuestos estatales y federales, no había mecanismos compensatorios para los estados con menor nivel de desarrollo por medio de las participaciones. Buena parte de la base fiscal se encontraba ligeramente gravada. Asimismo, era necesario reducir las desigualdades regionales, incrementar la eficiencia recaudatoria, dar certidumbre e incrementar paulatinamente los ingresos de los gobiernos estatales y municipales, además de simplificar las obligaciones fiscales de los contribuyentes, razones de peso que dieron origen al Sistema Nacional de Coordinación Fiscal. Este sistema se instrumentó con el objetivo de armonizar el Sistema Fiscal Federal con los equivalentes en los estados, municipios y Distrito Federal. Punto central es establecer la participación que les corresponda en los ingresos federales con base en sus haciendas públicas, así como distribuir entre estos las debidas participaciones con base en la Ley de Coordinación Fiscal (LCF).

El estado de Chiapas es altamente dependiente de los recursos federales y de estos fondos anotados en particular, por ejemplo, los ingresos estatales derivados de aplicar las potestades tributarias del Estado sumaron hasta septiembre del ejercicio fiscal del 2012, 3,804.0 millones de pesos, que representa tan solo el 7.6 $\%$ del total de los ingresos percibidos en el ejercicio 2011.

De esa forma, los recursos federalizados constituidos por las participaciones, aportaciones fiscales federales, constituyeron el $78.4 \%$ del total de ingresos obtenidos en el periodo de enero a septiembre del 2012, equivalente a 39515.9 millones de pesos. Así mismo, las transferencias, asignaciones y subsidios, representaron el $12.8 \%$, los cuales ascendieron a 6459.0 millones de pesos, cifra superior en 6.1 $\%$ con respecto a lo programado al 30 de septiembre de 2012, y un avance del $79.2 \%$ respecto a lo previsto en la Ley de Ingresos para 2012. En ingresos por 
financiamiento se obtuvo en el periodo de enero a septiembre 2012, la cantidad de
614.0 millones de pesos, supuestamente para fortalecer las finanzas estatales.

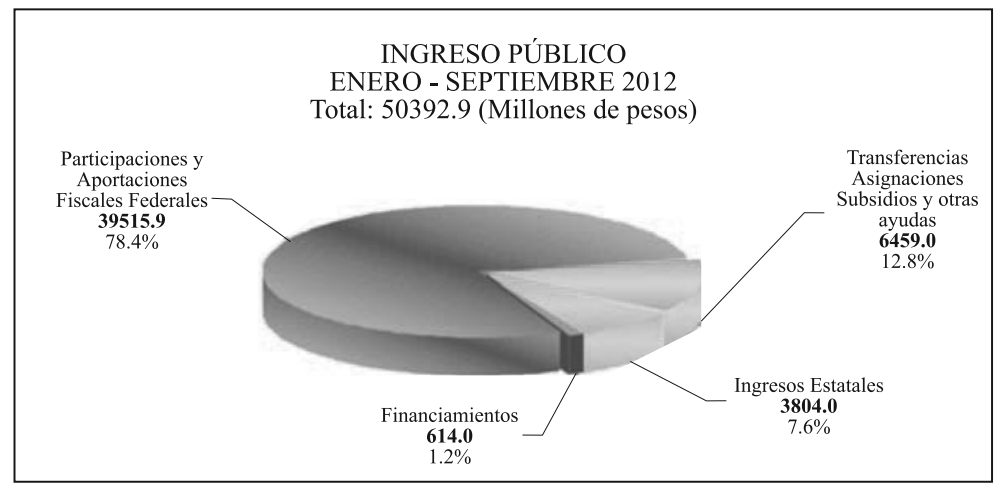

Figura 4. Ingreso público enero-septiembre 2012

Fuente: Secretaría de Hacienda del Gobierno del Estado de Chiapas

La debilidad estructural de las finanzas públicas queda demostrada en la alta dependencia por los recursos federales, ya que 9 de cada 10 pesos que ingresan al gobierno estatal vienen de recursos federales.

Ello sitúa a Chiapas como uno de los estados con mayor debilidad estructural de sus finanzas, muy por debajo del promedio de las diferentes entidades de la república y del nivel de comparaciones internacionales. La estructura de ingresos no se ha modificado a lo largo de ya casi veinte años. Por ejemplo, en el año de 1995, los ingresos gubernamentales de Chiapas ascendieron a 4927 millones de pesos a precios corrientes, de los cuales solamente 455 millones provenían de ingresos propios, dependiendo desde entonces de las participaciones federales, los subsidios y los incentivos por la administración de impuestos federales.

Como podemos observar en la Figura 5 , los ingresos propios del estado de Chiapas han estado en los últimos 16 años por debajo del $10 \%$ con relación a los ingresos totales; lo que muestra la alta dependencia del estado de los recursos federales; situación que ha llevado a la contratación de deuda pública, los procesos de bursatilización (colocación de obligaciones financieras en la Bolsa Mexicana de Valores) y a la necesidad de replantear la política de ingresos del estado. Hay que resaltar que en los últimos años el peso de los ingresos propios disminuyó notablemente comparado con los años 90. 


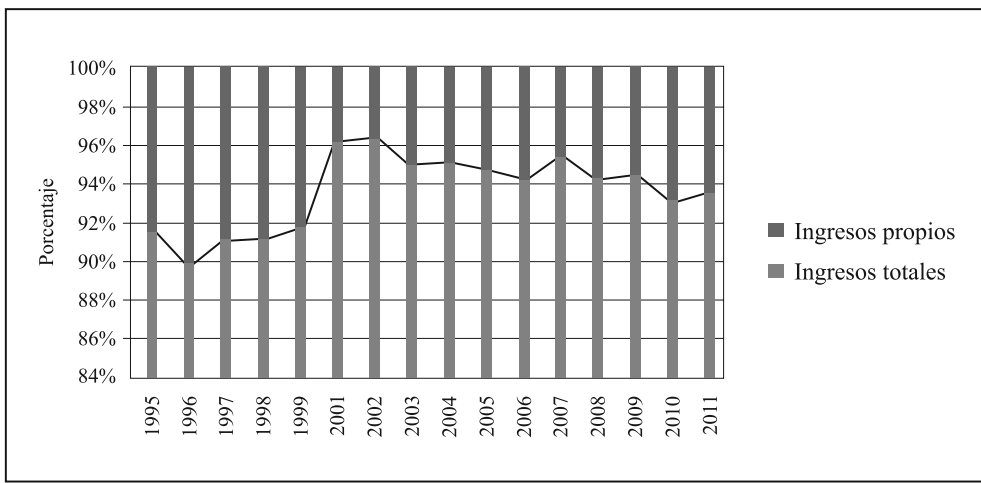

Figura 5. Ingresos totales del estado de Chiapas. Porcentaje de ingresos propios 1995-2011 Fuente: elaboración propia con base en las cuentas públicas del estado de Chiapas 1995-2011.

Pese a que los ingresos propios no han aumentando su participación porcentual dentro del total de los ingresos de Chiapas, se debe recalcar que sustancialmente han aumentado las participaciones y aportaciones federales al estado en los últimos lustros. Ello se enmarca claramente en el sistema de coordinación fiscal que se mencionó anteriormente, pero también en la estrategia de contrainsurgencia que se construyó en la década de los 90, para frenar la influencia del EZLN y de otras organizaciones sociales de izquierda en dicha entidad.

De tal forma, tenemos que los ingresos públicos de Chiapas pasaron de 4,927 millones de pesos en el año de 1994 a 69,552 millones de pesos en el año 2011 en precios corrientes; lo que muestra que, en cuanto a ingresos, estos aumentaron 14 veces en estos casi 20 años, 10 cual contrasta con la ineficiencia de la utilización del gasto público para resolver las graves carencias sociales que tiene el estado de Chiapas.
La deuda pública de Chiapas ha aumentado paulatinamente en estos últimos lustros. Llama sobremanera la atención el endeudamiento explosivo que experimentó el Gobierno de Juan Sabines Guerrero, ya que se pasó de un endeudamiento situado en alrededor de 1,000 millones de pesos, a una deuda que algunos calculan cercana a los 40,000 millones de pesos (incluyendo sobre todo pasivos a corto plazo que no se registraron ante la SHCP).

Lo cierto es que en Chiapas, en función de sus finanzas públicas, no hay grandes avances, ya que sigue dependiendo de las transferencias públicas del Gobierno federal y de las remesas, sus ingresos propios son mínimos y no generan condiciones para pagos futuros de la deuda; se tiene que recurrir al gobierno federal o implorar un rescate que no llega. Chiapas destaca como una administración pública que es permanentemente fiscalizada. El Gobierno del estado realiza en promedio 290 auditorías a dependencias, entidades 
y ayuntamientos; a lo anterior habrá que sumar las auditorías ordenadas por la federación (Auditoría Superior y Función Pública). El $6^{\circ}$ Informe del Gobierno Federal de Felipe Calderón señaló que Chiapas fue de las entidades con mayor número de observaciones, lo cual nos habla de las incapacidades de las entidades gubernamentales para comprobar efectivamente el gasto público. Transparencia Mexicana en su Índice Nacional de Corrupción y Buen Gobierno 2010, ubica a Chiapas en el lugar 17 con un índice de 7.6; el Estado de México y el Distrito Federal con 16.4 y 17.9 respectivamente, son los estados mejor posicionados.

Se observa que la deuda sigue aumentando en el Gobierno actual de Manuel Velasco Coello, y que hasta ahora no se conoce el monto total, de corto y largo plazo. La deuda puede atribuirse a varios aspectos: contratación de deuda por parte de Manuel Velasco Coello, deuda inercial, que se viene arrastrando del periodo anterior, deuda de corto plazo que se convirtió en largo plazo, intereses no pagados y capitalizados, etcétera. La deuda de largo plazo en los primeros seis meses del Gobierno de Manuel Velasco Coello se ha incrementado en 1,904.1 millones de pesos (en el primer semestre de 2013 fue la cuarta entidad que más se endeudó del país, solo detrás de Chihuahua, Sonora y Nuevo León; y si se ve por ingresos, es la más pobre del país que se endeudó más, ocupa el primer lugar) (López, 2014). Para junio del presente año, las obligaciones financieras del estado de Chiapas y sus municipios, registradas ante la Secretaría de Hacienda y Crédito Público del Gobierno federal, ascendieron a 18,317 millones de pesos, lo cual nos habla de un incremento sustancial de la deuda en los últimos seis años.

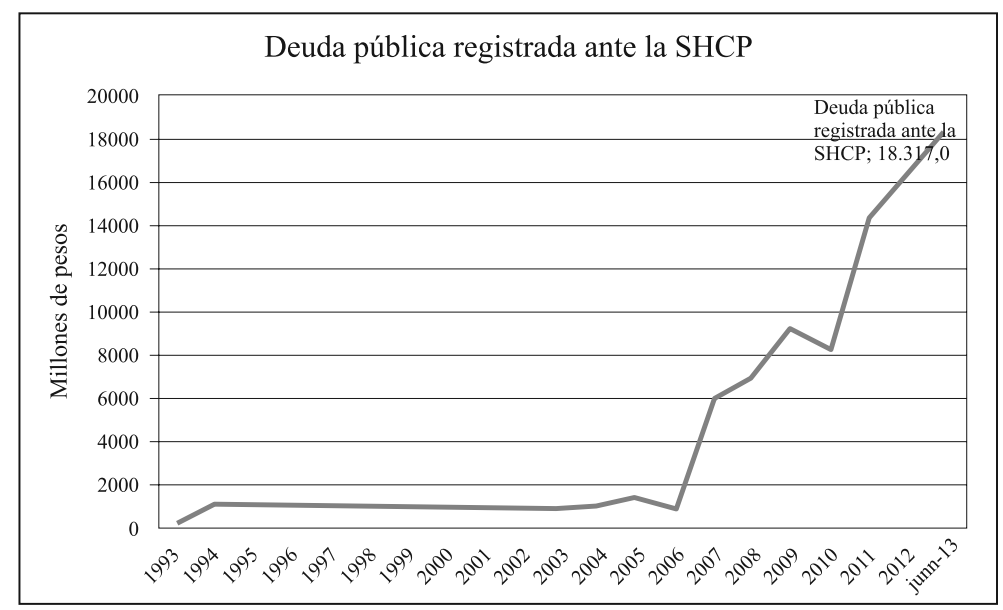

Figura 6. Deuda pública del estado de Chiapas 1993-2013 Millones de pesos a precios corrientes

Fuente: elaboración propia con datos de la SHCP. 
Esta contratación de deuda pública que han realizado las últimas dos administraciones, ha significado que el saldo de la deuda como porcentaje de las participaciones federales ha aumentado dramáticamente. Así, tenemos que para el 2006 las obligaciones financieras representaban el $6.8 \%$ de las participaciones federales de los ingresos públicos y para marzo del 2013 representaban el $74.5 \%$ del total de las participaciones. Es importante resaltar que el costo porcentual promedio al que se ha contratado la deuda, se encuentra por encima del promedio nacional, lo cual implica mayores sacrificios para los habitantes del estado de Chiapas. A ello se suma que la deuda pública en 1994 tenía un plazo de 8.6 años, en el año 2001 de 13.4 años, en el 2006 de 9.8 años y para junio de 2013 de 19 años; en síntesis, mayor tiempo para pagar y mayor tiempo de carga a los ingresos públicos. Se anota, además, que del total de las obligaciones financieras del estado de Chiapas a marzo del 2013, 15,303 millones de pesos correspondían a la deuda contraída por el Gobierno del estado, 896 millones de pesos a los municipios y 229 millones a organismos municipales. La deuda de Chiapas se multiplicó por 13 en el periodo 2006-2011, lo que ha hecho que este se encuentre entre los cuatro estados con mayor crecimiento en ese rubro, según cifras de la Secretaría de Hacienda y Crédito Público. En términos reales, la deuda chiapaneca registró un crecimiento de $1,199 \%$, al pasar de 882 millones a 14,226 millones de pesos en dicho lapso. También es importante señalar que en el crecimiento de la deuda per cápita, es decir, por habitante del estado, Chiapas tuvo una tasa media de crecimiento anual de $63.1 \%$ del año 2006 al 2010.

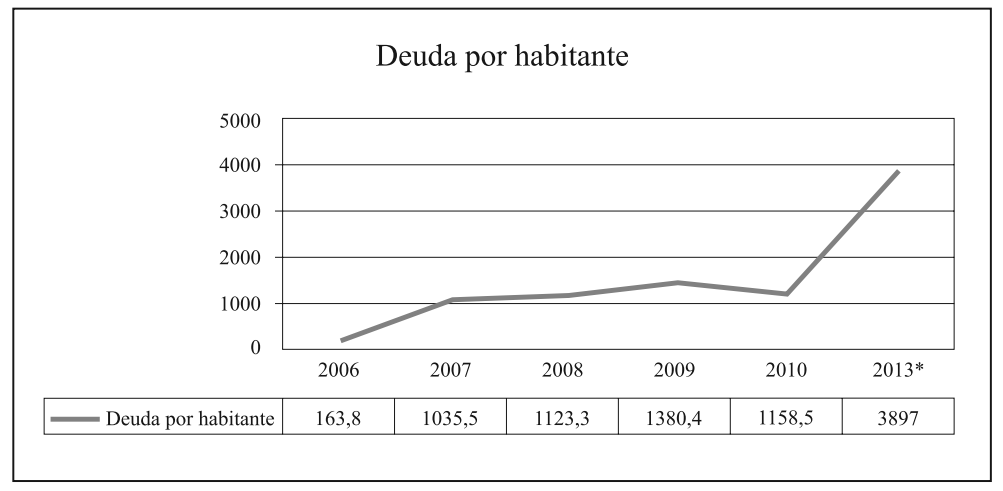

Figura 7. Deuda por habitante del estado de Chiapas 2006-2013

*Estimación para el año.

Fuente: elaboración propia con base en datos de la SHCP y del Dr. Jorge López Arévalo. 
Casi la tercera parte de las obligaciones financieras contraídas por el estado de Chiapas corresponde a la puesta en marcha de un fideicomiso de estrategias financieras multisectoriales (FIDEFIM), que emitió valores para colocar en la Bolsa Mexicana de Valores por un monto de cinco mil millones de pesos en mayo del año de 2007. Destaca dentro de este endeudamiento la gran comisión que se llevó la operadora de bolsa, el plazo de treinta años para su pago y la ausencia de mecanismos reales de transparencia.

Tabla 1. Emisiones bursátiles de Chiapas a junio 2013 (millones de pesos corrientes)

\begin{tabular}{|c|c|c|c|c|c|c|}
\hline Año & Emisor & $\begin{array}{c}\text { Fecha de } \\
\text { la emisión }\end{array}$ & $\begin{array}{c}\text { Monto de } \\
\text { la emisión }\end{array}$ & $\begin{array}{c}\text { Saldo de } \\
\text { la emisión }\end{array}$ & $\begin{array}{c}\text { Tipo de } \\
\text { garantía }\end{array}$ & $\begin{array}{c}\text { Plazo } \\
\text { (años })\end{array}$ \\
\hline 2007 & Chiapas & 28 de Junio & $4,200.0$ & $5,246.5$ & $\begin{array}{c}\text { Impuesto } \\
\text { sobre nómina } \\
\text { Impuesto } \\
\text { sobre nómina }\end{array}$ & 30 \\
\hline
\end{tabular}

Fuente: elaboración propia con datos de la SHCP.

Para manejar muchos de los recursos públicos, el Gobierno de Juan Sabines Guerrero puso en marcha más de 41 fideicomisos, los cuales no pueden ser auditados, debido al secreto bancario, pero que en conjunto manejaron una cantidad cercana a las obligaciones financieras colocadas en la Bolsa Mexicana de Valores. Entre ellos destacan: Fideicomiso Fondo para la Atención de Niñas, Niños y Jóvenes Migrantes (FANIJOMI), Fideicomiso de Apoyo a las Actividades Pecuarias del Estado de Chiapas (FIMEGEN) y Fideicomiso Fondo de Financiamiento para las Empresas de Solidaridad del Sector Artesanal de Chiapas (FOFESSA), Fideicomiso Programa Nacional de Becas y Financiamiento para la Educación Superior (PRONABES), Fideicomiso Agrario Ambiental del Gobierno del Estado (FIAAGE), Fideicomiso para el Desarrollo Industrial del Estado de Chiapas (FIDEIN), Fideicomiso Fondo de Apoyo a los Jóvenes Empresarios Chiapanecos (FONAJECH) y Fideicomiso Liquidador de Activos Financieros y de Financiamiento a Sectores Estratégicos (FLAFFISE). Al mes de julio: Fideicomiso para la Construcción y Desarrollo Integral de una Villa Rural Sustentable en el Municipio de Tecpatán, Chiapas (VILLA RURAL) y Fideicomiso del Café de Chiapas (FICAFÉ), Fideicomiso Fondo Estatal para la Atención de Desastres Naturales (FOEADEN 1987), Fideicomiso Fondo de Seguridad Pública del Estado de Chiapas (FOSEG), Fideicomiso de Fomento para la Asistencia Social de Chiapas (FAS), Fideicomiso Una Mano... Una Esperanza, Fideicomiso Fondo para la Educación y Salud de la Infancia Chiapaneca (FOESICH), Fideicomiso de Apoyo para 
la Atención de Personas Mayores de 64 años (FAAPEM'64), Fideicomiso para el Desarrollo Estratégico del Aeropuerto Internacional Ángel Albino Corzo (AEROPUERTO) y Fideicomiso para el Mejoramiento Integral de Poblados del Estado de Chiapas (FIMIP), entre otros.

\section{EL ESTADO DE CHIAPAS A VEINTE AÑOS}

Chiapas ocupa una extensión territorial de $73,289 \mathrm{~km}^{2}$, que representa el $4 \%$ de la superficie del país; tiene una población de 4.800,000 habitantes, con una tasa media anual de crecimiento poblacional del 2.2 $\% ; 0.4 \%$ superior a la nacional que es de $1.8 \%$, ambas comprendidas en el periodo 2005-2010. (INEGI, 2011)

En términos concretos, hace veinte años Chiapas se caracterizaba por la desigualdad y la discriminación de los pueblos indígenas. En Chiapas existen $1.142,000$ personas hablantes de lengua indígena, que representa el $27 \%$ de la población total del estado, es decir, uno de cada cuatro chiapanecos es indígena. El estado ocupa el primer lugar en monolingüismo en el país (INEGI, 2011). La tierra donde uno de cada tres no sabía leer o escribir, y dos de cada cinco tenían hambre (INEGI, 1995; Coneval, 1990). El de los 2.3 millones de pobres, el de los 1.2 millones sin agua, los 1.5 millones sin piso firme, y el del millón sin drenaje (Coneval, 1990). El Chiapas de 1994 era el estado más pobre del país, el que tenía mayor grado de analfabetismo, el que más carecía de electricidad, el que más padecía de hacinamiento, y en el que más individuos ganaban dos o menos salarios mínimos (Coneval, 1990; Conapo, 1990; INEGI, 1995).

A veinte años de distancia, según cifras del Consejo Nacional de Evaluación de la Política Social en México (CONEVAL), Chiapas es más pobre hoy que en 1994. El día del levantamiento zapatista las cifras mostraban que el $75 \%$ de la población del estado no tenía ingresos suficientes para cubrir sus necesidades básicas patrimoniales. Hoy la cifra asciende a $78 \%(3.778,000)$ de la población total del estado. De estos, el $46 \%(2.197,000)$ se ubica en condiciones de pobreza moderada; y el $33 \%(1.581,000)$ está en condiciones de pobreza extrema. (CONEVAL, 2010; Ríos, 2014).

En un análisis de la Encuesta Nacional de Ingreso Gasto de los Hogares (ENIGH), el CONEVAL también da cuenta del comportamiento en los últimos años de los indicadores de pobreza, pese a que en el ámbito de política pública se formuló como uno de los objetivos del milenio erradicar dicho problema social.

Así, somos testigos de que los indicadores de carencia social siguen muy por encima de la media nacional. Se destaca el rezago educativo, la carencia de acceso a la seguridad social, la mala calidad y falta de espacios en la vivienda, la ausencia de servicios básicos en los hogares y la mala alimentación. Casi 8 de cada 10 chiapanecos se encuentra por debajo de la línea de bienestar. 
De igual forma, 90 de los 122 municipios del estado (74\%), se encuentran con un alto o muy alto grado de marginación; tan solo dos municipios tienen un grado de marginación bajo y muy bajo: Reforma y Tuxtla Gutiérrez, respectivamente. Según CONAPO (2013), Chiapas se ubica dentro de los estados con el más alto grado de marginación a nivel nacional (tercer lugar), el cual hace referencia a educación, servicios básicos, vivienda, empleo y dispersión comunitaria.

Comparado con el resto de los estados de la república mexicana, Chiapas es uno de los cuatro estados que ha aumentado su pobreza, sigue siendo el estado más pobre de México y mucho más de lo que era en 1994. Según datos del CONEVAL, en Chiapas también en estos veinte años, la pobreza alimentaria ha aumentado sustancialmente. El estado de Chiapas es el más hambriento del país, ya que más de la mitad de la población sufre hambre por encima del promedio nacional que es de $18 \%$.
En Chiapas existe una estructura institucional conformada por 68 dependencias, de las cuales 18 son secretarías de estado, 2 institutos, 13 organismos desconcentrados, 30 organismos públicos descentralizados, 3 organismos auxiliares del ejecutivo y 2 empresas de participación estatal. La administración pública centralizada ocupa un total de 55.289 personas, de las cuales el $46 \%$ es personal docente, el $40 \%$ de confianza, el $8 \%$ de base y el 6 $\%$ temporal. (PDE, 2012).

El aumento de recursos públicos vía participaciones, aportaciones, transferencias y endeudamiento, no se ha traducido en una mayor eficiencia gubernamental, como se puede observar en la Tabla 2, donde el estado tiene un mayor número de funcionarios por cada mil habitantes (24.53 funcionarios por cada mil habitantes), pero donde ellos realizan una cuarta parte de los tramites que en promedio se llevan a cabo a nivel nacional. A escala nacional, un funcionario realiza un promedio de 67.59 trámites, y en el estado de Chiapas, tan solo 14.51 por funcionario.

Tabla 2. Chiapas: funcionarios en la administración pública y por habitante, 2010

\begin{tabular}{|c|c|c|}
\hline Ámbito & Población total & $\begin{array}{c}\text { Funcionarios por } \\
\text { cada } 1000 \text { habitantes }\end{array}$ \\
\hline Nacional & 112336538 & 15.17 \\
\hline Chiapas & 4796580 & 24.53 \\
\hline Nacional & Funcionarios totales & Trámites por funcionario \\
\hline Chiapas & 1704568 & 67.59 \\
\hline
\end{tabular}

Fuente: elaboración propia con base en INEGI.Encuesta Nacional Gobierno 2011. 
Si se utilizan algunos indicadores financieros para analizar el comportamiento de las finanzas públicas chiapanecas del 2002 al 2011, se puede concluir que la autonomía financiera ha aumentado, existe una dependencia muy alta de las participaciones y de las aportaciones federales, la capacidad de inversión se ha incrementado, aunque la capacidad de inversión social se mantiene casi igual después de una década. Como ya se anotó, el peso del servicio de la deuda ha aumentado considerablemente, pero ello no se ha traducido en un incremento del costo burocrático, aunque los costos de operación del Gobierno se mantienen casi iguales. Como se cuenta con mayores ingresos públicos, los ingresos per cápita se han incrementado. En términos corrientes, el gasto en obra pública y gasto social se han incrementado, se ha duplicado el PIB per cápita y la deuda pesa cada vez más sobre los ingresos disponibles:

Tabla 3. Indicadores financieros del estado de Chiapas 2002-2011

\begin{tabular}{|c|c|c|}
\hline Indicador & 2002 & 2011 \\
\hline $\begin{array}{c}\text { Autonomía financiera }=\text { (ingresos } \\
\text { propios/gasto total }) * 100\end{array}$ & 3.66 & 5.75 \\
\hline $\begin{array}{l}\text { Dependencia de participaciones federales }= \\
\quad(\text { participaciones / ingresos totales }) * 100\end{array}$ & 34.27 & 28.77 \\
\hline $\begin{array}{l}\text { Dependencia de aportaciones federales }= \\
\quad(\text { aportaciones / ingresos totales }) * 100\end{array}$ & 60.37 & 52.18 \\
\hline $\begin{array}{c}\text { Capacidad de inversión }=\text { (gasto de inversión } \\
\qquad / \text { gasto total }) * 100\end{array}$ & 7.85 & 9.37 \\
\hline $\begin{array}{l}\text { Capacidad de inversión social }=(\text { gasto en obra } \\
\text { pública y acciones sociales / gasto total }) * 100\end{array}$ & 4.50 & 4.54 \\
\hline $\begin{array}{c}\text { Peso del servicio de la deuda }= \\
(\text { deuda } / \text { gasto total }) * 100\end{array}$ & 1.99 & 2.53 \\
\hline $\begin{array}{l}\text { Costo burocrático }=(\text { gasto en servicios } \\
\text { personales / gasto total }) * 100\end{array}$ & 19.84 & 14.79 \\
\hline $\begin{array}{c}\text { Costo de operación }=(\text { gasto corriente } \\
\qquad / \text { gasto total }) * 100\end{array}$ & 68.88 & 62.29 \\
\hline $\begin{array}{c}\text { Ingresos propios per cápita }= \\
\text { (ingresos propios / población) (pesos corrientes) }\end{array}$ & 210.52 & 802.66 \\
\hline $\begin{array}{l}\text { Gasto en obra pública y acciones sociales } \\
\text { per cápita = (gasto en obra pública y acciones } \\
\text { sociales / población) (miles de pesos corrientes) }\end{array}$ & 258.43 & 634.76 \\
\hline PIB per cápita $=($ PIB $/$ población $)($ pesos corrientes $)$ & $20,122.37$ & $42,238.79$ \\
\hline $\begin{array}{l}\text { Importancia del servicio de la deuda en los } \\
\text { ingresos disponibles }=[(\text { deuda }) /(\text { ingresos } \\
\text { propios }+ \text { participaciones }+ \text { FAFEF })] * 100\end{array}$ & 4.91 & 6.94 \\
\hline
\end{tabular}

Fuente: elaboración de los autores con base en datos de la SHCP e INEGI 
Todo el desempeño gubernamental tiene que ver con la capacidad con que los ciudadanos intervienen en los asuntos públicos y logran incidir realmente en la gestión pública, para mejorar el uso del gasto público y hacer frente a la corrupción. En México, la Confederación Patronal Mexicana (COPARMEX) construyó un Índice de Desarrollo Democrático donde, desafortunadamente, Chiapas se encuentra en los últimos lugares.

\section{CONCLUSIONES}

La presente investigación permitió acercarse a la situación de las finanzas públicas de Chiapas, para dar cuenta de cómo la mayor llegada de recursos fiscales no ha permitido avanzar positivamente en la erradicación de la pobreza y de las carencias sociales de la mayor parte de la población. La creciente afluencia de recursos no ha permitido al estado de Chiapas posicionarse y enfrentar las causas que hicieron posible el alzamiento zapatista de hace veinte años, muchas de las razones estructurales se han profundizado con la puesta en marcha de las reformas neoliberales y el Tratado de Libre Comercio de América del Norte (TLCAN), el campo chiapaneco ha perdido su importancia como sector generador de empleos y por lo tanto crecientemente se impulsan procesos migratorios, donde se visualiza al estado de Chiapas como uno de los estados donde la emigración crece fuertemente a Estados Unidos de América. Además, el precio del café continúa deprimido. Como alternativas a esta situación, el estado visualiza el modelo extractivista minero y la producción de agrocombustibles cuyos costos sociales y ambientales serían muy altos para los habitantes de este estado.

La alternativa es construir instituciones y observatorios civiles que puedan garantizar un mejor ejercicio del gasto público con transparencia y la introducción fuerte de la cultura de rendición de cuentas a la ciudadanía. Además, debe visualizarse la elaboración de planes de desarrollo donde participen efectivamente las comunidades indígenas, se reconozcan plenamente sus derechos y su cultura y se cumplan los acuerdos de San Andrés, sobre todo, en el marco de respeto a los usos territoriales que pueden disponer las comunidades indígenas.

Como plantea John Ackerman (2008, p. 16)

la rendición de cuentas debe entenderse como un proceso dinámico y no como un momento estático. Rendir cuentas es estar en constante movimiento y no permanecer sentado en la oficina portándose bien y estando abierto a la crítica. Rendir cuentas es salirse de la oficina, dialogar con la sociedad y establecer contacto con otras instituciones en lugar de esconderse de la vigilancia ciudadana. El comportamiento pro activo que implica la rendición de cuentas exige constante diálogo, explicación y justificación de las acciones gubernamentales. 
Para que exista una efectiva rendición de cuentas se requiere una mayor participación e involucramiento de la ciudadanía. La participación de la sociedad civil en la definición, implementación, monitoreo y evaluación de políticas y programas sociales presenta numerosos beneficios. Primero, la participación mejora la eficiencia en la asignación de recursos y la eficacia de aquellos programas, permitiendo que los propios destinatarios puedan expresar sus verdaderas necesidades. Segundo, la participación incrementa la eficiencia de las políticas públicas por medio del establecimiento de alianzas con organizaciones de la sociedad civil, que muchas veces llegan donde el Estado no lo hace y con menores costos. Tercero, incluir a actores clave de la sociedad civil en el monitoreo de programas y proyectos permite elevar la transparencia de los mismos, reduciendo las posibilidades de corrupción y, en definitiva, logrando que los recursos existentes lleguen a más hogares, en más regiones y por más tiempo.

\section{REFERENCIAS}

Ackerman, J. (2008). Introducción: más allá del acceso a la información. En J. Ackerman (coord.) Más allá del acceso a la información. Transparencia, rendición de cuentas y estado de derecho. México: Siglo XXI.

Ávila, L. (2012). Las estrategias sustentables de desarrollo autónomo en Chiapas. ¿Es Posible Generar Alternativas a la Mundialización? Madrid, España: Editorial Académica Española.

Burguete, A. (2012). Gobierno y provisión de servicios en municipios indígenas del estado de Chiapas. México: PNUD.

Calva, J. (1993, 19 de feb.). Raíz y razón de Chiapas. Periódico El Financiero.

Consejo Nacional de Evaluación de la Política de Desarrollo Social-CONEVAL-. (2009). Medición de pobreza 2010 por entidad federativa. Recuperado de http://internet. coneval.gob.mx/ Informes/Interactivo/interactivo_entidades.swf

Consejo Nacional de Población, Contexto Social -CONAPO-. (2005). Índice de marginación. Recuperado de http://www.inee.edu.mx/bie/mapa_indica/2005/PanoramaEducativoDeMexico/ CS/CS10/2005_CS10_.pdf

Consejo Nacional de Población, Contexto Social-CONAPO-. (s.f.). Contexto social. Indicadores demográficos básicos 1990-2030. Consejo Nacional de Población.

García de León, A. (1985). Resistencia y utopía. Memorial de agravios y crónicas de revueltas y profecías acaecidas en la provincia de Chiapas durante los últimos quinientos años de su historia. 2 volúmenes. México: Era. 
El estado mexicano de Chiapas: ¿Qué ha cambiado en veinte años?

Agustín Ávila Romero - José Luis Sulvarán López - León Enrique Ávila Romero

González, P. (1995). Causas de la rebelión en Chiapas. Periódico La Jornada, suplemento "Perfil".

Gobierno del Estado de Chiapas, Secretaría de Hacienda. (2012). Guía metodológica para la elaboración del plan de desarrollo municipal 2012-2015.

Gobierno del estado de Chiapas. Secretaría de Hacienda. (2010). Presupuesto devengado 2010.

Gobierno del estado de Chiapas. (2007). Programa sectorial desarrollo económico 2007-2012.

Harvey, N. (1995). Reformas rurales y rebelión zapatista: Chiapas 1988-1994. En Paisajes rebeldes. (p. 214). México: UIA.

Instituto Mexicano para la Competitividad. (2010). Chiapas análisis de competitividad. México: IMC.

Instituto Nacional de Estadística, Geográfica e Informática-INEGI-. (2010). Censo de población y vivienda 2010. Recuperado de $h t t p: / / w w w$ inegi.org.mx/est/contenidos/proyectos/ccpv/cpv2010/ Default.aspx

Instituto Nacional de Estadística, Geográfica e Informática -INEGI-. (2010). México en cifras. Información nacional por entidad federativa y municipios 2010. México: Instituto Nacional de Estadística y Geografía.

Instituto Nacional de Estadística, Geográfica e Informática-INEGI-.(2011). Anuario Estadístico 2011. Recuperado de http://www.inegi.org.mx

Instituto Nacional de Estadística, Geográfica e Informática -INEGI-. (2011). Encuesta Nacional de Gobierno.

Instituto Nacional de Estadística, Geográfica e Informática -INEGI-. (2011). Perspectiva estadística Chiapas. Recuperado de http://www.inegi.org.mx/sistemas/sisept/Defaultasp $\mathrm{x} ? \mathrm{t}=\mathrm{mdemo} 09 \& \mathrm{~s}=\mathrm{est} \& \mathrm{c}=17511$.

Le Bot, Y. (1997). El sueño zapatista. Entrevista con el subcomandante Marcos, el mayor Moisés y el comandante Tacho del EZLN. Barcelona: Plaza y Janés.

López, A. (1994). Causas del levantamiento en Chiapas. Revista Coyuntura.

López, J. (2014). Chiapas paralelo. Recuperado de www.chiapasparalelo.com.mx

Plan Estatal de Desarrollo -PED-. (2013). Chiapas.

Registro Agrario Nacional -RAN-. (2002). Estado de la situación agraria de ejidos en México. México: RAN.

Ríos, V. (2014, enero). Chiapas peor que ayer. Revista Nexos.

Vásquez, A. (1994, marzo-abril). Algunas causas que explican el levantamiento armado en Chiapas. El Cotidiano, (61), 29. 